\title{
Uma contribuição ao movimento instituinte do Sistema \\ Nacional de Educação
}

\section{A contribution to the National Education System institutionalization movement Una contribuición para el movimiento instituyente del Sistema Nacional de Educación \\ MARIA BEATRIZ LUCE NALÚ FARENZENA}

\begin{abstract}
Resumo: A instituição do Sistema Nacional de Educação é uma questão central no atual momento histórico; é balizada pela agenda do Plano Nacional de Educação (2014-2024). Neste artigo apresentamos os dois documentos considerados seminais na construção de consensos ou acordos em torno de temas do movimento instituinte do Sistema Nacional de Educação, produzidos pela SASE/MEC. Situamos também o legado normativo e a arena política em que estamos desafiados a lutar, mais uma vez, por maior intensidade democrática para garantir o direito de todos à educação.
\end{abstract}

\begin{abstract}
The establishment of a National Education System is a central issue in the current historical moment of Brazil, framed within the National Education Plan (2014 - 2024) agenda. In this article we present two documents published by the Ministry of Education, which are considered seminal in the building of consensus or agreements for the institutionalization of the National Education System. Also, we review the normative legacy and the political arena in which we are challenged to fight, once again, for greater democratic intensity in order to ensure the right to education for all.
\end{abstract}

Resumen: La institución del Sistema Nacional de Educación es una cuestión central en el actual momento histórico de Brasil; es enmarcada por la agenda del Plan Nacional de Educación (2014-2024). En este artículo presentamos los dos documentos considerados seminales en la construcción de consensos o acuerdos acerca de temas del movimiento instituyente del Sistema Nacional de Educación, producidos por la SASE/MEC. Situamos también el legado normativo y la arena política en que estamos desafiados a luchar, otra vez, por más intensidad democrática para garantizar el derecho de todos a la educación.

\section{INTRODUÇÃO}

Vivemos mais um momento histórico de intensos debates acerca das políticas públicas de educação no Brasil, no qual a instituição do Sistema Nacional de Educação é uma questão central e balizada pela agenda do Plano Nacional de Educação (2014-2024). Entendemos, pois, como urgente uma forte mobilização para alargar a rede dos que se interessam, se posicionam e contribuem ao 
movimento instituinte deste dispositivo político-normativo, porque necessário alçar uma perspectiva conceitual e programática consoante às expectativas com as quais foi inserido no ordenamento constitucional e legal do Brasil: garantir a todos os cidadãos direito à educação com padrão de qualidade, dever próprio do Estado federativo.

Por essa razão, propusemos que a Revista Brasileira de Política e Administração da Educação, em uma seção Documentos, reproduzisse dois textos que foram publicados pelo Ministério da Educação, por iniciativa de sua Secretaria de Articulação com os Sistemas de Ensino (SASE), considerados seminais na construção dos consensos ou acordos em torno dos temas e iniciativas relativas ao movimento instituinte do Sistema Nacional de Educação (SNE). Dessa forma, ficariam estes preservados em páginas de 2015, o $31^{\circ}$ ano deste periódico, que já atinge um elevado reconhecimento acadêmico-científico; ao mesmo tempo que acessíveis ao amplo número de leitores de suas versões impressa e digital. Com o pronto acolhimento das novas editoras da $\mathrm{RBPAE}^{1}$ e um estímulo manifesto pelo Presidente da ANPAE, obtivemos a autorização devida ${ }^{2}$ e nos dispusemos a elaborar um texto de introdução.

No entanto, além de cumprir este compromisso, o trabalho que seria de menor monta acabou por nos chamar a mais uma oportunidade de (re)leituras em diálogo, no mesmo sentido de pesquisa reflexiva e propositiva que nos une no cotidiano acadêmico e nos reúne frequentemente com os companheiros da ANPAE e de um amplo campo político-educacional, ao longo de um percurso em que temos sido analistas e artífices - como pesquisadores, professores e militantes - do movimento histórico em que procuramos mais gestão democrática da e na educação ${ }^{3}$. Descobrindo e esculpindo, de concepções a vivências - ou viceversa, nos constituímos cada qual e todos com ideias, discursos e práticas em que compartilhamos este propósito. Com efeito, as publicações, assim como os congressos associativos e os projetos de pesquisa, de formação e de administração, nos levam ao instituído e ao instituinte da política e gestão da educação. Instituído, o estabelecido em leis e regulamentos próprios da organização em sociedade, oferece as diretrizes de estrutura e funcionamento das instituições e das relações entre estas. Instituído, de pronto passa a requerer nosso investimento, esforço e vigilância crítica para a defesa dos interesses do bem comum e o respeito à coisa pública. Instituinte, o próprio movimento histórico de percepção e formulação de novas demandas e novas agendas, seja porque se abrem espaços à organização

1 Lúcia Maria de Assis e Daniela Costa Lima, professoras da Universidade Federal de Goiás, que assumiram a editoria da RBPAE na gestão do presidente da ANPAE (2015-2017), João Ferreira de Oliveira.

2 Originais cedidos pela Diretoria de Articulação com os Sistemas de Ensino, MEC/SASE.

3 Como situado em MEDEIROS; LUCE (2006). 
e voz de setores da sociedade menos contemplados ou que se modificam, como porque se vão reconhecendo necessidades e limites, possibilidades e obstáculos que não haviam ainda sido reconhecidos.

O movimento instituinte do Sistema Nacional de Educação é esteado no artigo 214 da Constituição Federal e na Lei n. ${ }^{\circ}$ 13.005/2014, que o atende por aprovar o Plano Nacional de Educação. Há, assim, uma realidade educacional de assimetrias educacionais que nos compelem a equalizar as oportunidades para todos; e direitos e deveres em matéria de educação escolar que, instituídos, estão ainda carecendo de meios e formas para sua concretização. O PNE foi concebido para "articular o Sistema Nacional de Educação em regime de colaboração e [...] assegurar a manutenção e desenvolvimento do ensino em seus diversos níveis, etapas e modalidades por meio de ações integradas dos poderes públicos das diferentes esferas federativas ..." (Constituição federal, art. 214, caput). Cumprenos agora e com vistas a um futuro próximo mobilizarmos nossas capacidades de estudo, discussão e produção de acordos para viabilizar os desígnios da institucionalização do PNE, na perspectiva de construção do Sistema Nacional de Educação.

A contribuição ao movimento instituinte do Sistema Nacional de Educação, que fazemos introduzindo-o neste número da RBPAE, por meio da seção Documentos, tem a intenção de subsidiar e de chamar o debate. Daí, uma breve caracterização dos dois textos publicados por iniciativa do Ministério da Educação e, a seguir, dois pontos que consideramos com possibilidades conclamadoras de estudos e discussões sobre o instituído e o instituinte: um recordatório do legado normativo e um breve mapeamento de posições ideológicas e de atores na arena de debates e deliberações sobre o Sistema Nacional de Educação. Concluímos o artigo nos apropriando, mais uma vez, de Boaventura de Sousa Santos (2000), para quem a luta por maior intensidade democrática é um movimento [instituinte] sem fim; e, assim, reafirmando que esta, sendo fonte inesgotável do aperfeiçoamento humano, tem na e para a educação uma primordial sustentação.

\section{OS DOCUMENTOS: O SISTEMA NACIONAL DE EDUCAÇÃO E A SUA AGENDA INSTITUINTE}

Motivam esta seção dois documentos, produzidos na Secretaria de Articulação com os Sistemas de Ensino do Ministério da Educação, pelo diálogo entre dirigentes e estudiosos de política e administração da educação, especialmente convidados. Não apenas por coincidência, estes são vinculados à ANPAE e a outras proeminentes entidades representativas dos pesquisadores e professores brasileiros, como associados e participantes ativos em congressos e 
seminários, autores em suas publicações. Contam com amplo reconhecimento da comunidade acadêmica, em âmbito nacional; e, mais uma vez, se dedicam a um estudo de alta relevância para a educação no País, pelo que também cabe louvar a oportuna e qualificada iniciativa da SASE/MEC.

Os documentos estão disponíveis no portal eletrônico "Planejando a Próxima Década - construindo os planos de educação", em www.pne.mec. gov.br/publicacoes, e são intitulados como: O Sistema Nacional de Educação; e Instituir um Sistema Nacional de Educação - agenda obrigatória para o país.

Foram produzidos em sequência temporal - 2014 a 2015 -, o que pode comprovar a densidade do trabalho intelectual envolvido mas também que este avançou em consonância com a aprovação do Plano Nacional de Educação e a realização da Conferência Nacional de Educação (CONAE) de 2014, assim como com a extensão dos estudos e debates que tem sido feitos com as secretarias e conselhos estaduais e municipais de educação, visando a capilaridade do planejamento articulado nos sistemas de ensino. Daí, igualmente, a sua relevância e potencialidade seminal.

Ao reconhecermos o valor de construção histórica dos documentos aqui destacados, ousamos buscar em poucas palavras identificá-los a cada um, na unidade que perfazem: um substantivo, o outro verbo; um de orientação conceitual, o outro diretrizes para a ação.

\section{O Sistema Nacional de Educação}

É o documento que contextualiza, fundamenta e propõe uma expressão conceitual e uma forma de dar consistência normativa e institucional ao Sistema Nacional de Educação, com o objetivo de propor linhas gerais para os primeiros acordos sobre o tema e estimular discussões em todo o país para a construção de uma proposta coletiva que encontre eco no Congresso Nacional.

Tem como principal ponto de referência a Constituição Federal, no que tange à estrutura da República Federativa do Brasil e aos princípios da cooperação entre os entes federativos (art. $23, \mathbb{\$} 1^{\circ}$ ) e do regime de colaboração entre os sistemas de ensino (art. 211), como no que dispõe sobre o direito à educação, dando destaque às conquistas da Emenda Constitucional n. ${ }^{\circ}$ 59/2009. Afirma, por conseguinte, que o Sistema Nacional de Educação já existe, porque previsto no artigo 214 da Constituição Federal; e que deve ser instituído no prazo de dois anos após a vigência do Plano Nacional de Educação (Lei n. ${ }^{\circ}$ 13.005/2014), ou seja, até 24 de junho de 2016. Trata, então, do que está por definir: diretrizes, metas, recursos e estratégias de manutenção e desenvolvimento da educação básica e superior, salientando o desafio de garantir a universalização da educação 
básica dos 4 aos 17 anos, em regime de colaboração.

Elaborado por Carlos Augusto Abicalil, Carlos Roberto Jamil Cury, Luiz Fernandes Dourado e Romualdo Portela, como convidados eternos; e Binho Marques, Flávia Nogueira e Maria Beatriz Luce, pelo Ministério da Educação, este documento foi concluído em julho de 2014 e tornado público no dia 9/10/2014, em http:// pne.mec.gov.br/images/pdf/sase_mec.pdf. Dele destacamos a frase derradeira: "A grande tarefa nacional e desafio histórico é dar consistência ao SNE para a garantia do direito constitucional [à educação]".

\section{Instituir um Sistema Nacional de Educação - agenda obrigatória para o país}

Embora não retome a frase que acabamos de citar, podemos aqui percebê-la como um elemento de ligação entre ambos os documentos. Denota o próprio título deste, que tem o sentido de dar sequência e promover sequência. É um documento, nitidamente, de suporte ao movimento instituinte do Sistema Nacional de Educação, com a intenção de dar-lhe consistência no processo de implementação do Plano Nacional de Educação (2014-2014). Como tal, mais informativo e propositivo mas fiel aos preceitos do antecedente, à linha de mobilização para os acordos necessários com vistas a uma proposta coletiva sobre os diversos dispositivos que precisam ser firmados em cooperação federativa, para o regime de colaboração entre os sistemas de ensino garantir o direito à educação.

O texto parte da noção geradora de educação com direito social, plasmada na Constituição Federal de 1998 para revisar o movimento do ordenamento legal de ampliação do direito à educação e de equalização das oportunidades educacionais; e, assim, indicar o grande avanço que significa o novo Plano Nacional de Educação, com explícita vinculação de recursos. Entretanto, frisa o desafiador paradoxo do presente: O PNE tem o designío de articular o Sistema Nacional de Educação mas este não está ainda instituído!

Com minuciosa análise dos elementos e estratégias estabelecidos no PNE 2014-2014 que propõem a agenda instituinte do SNE, definindo ações e estabelecendo prazos, os autores fundamentam que não bastará uma Lei para institui-lo. Será preciso um conjunto articulado de quatro dimensões que levem a uma nova forma de organização da educação nacional:

(I) Alterações na LBD, para inclusão de um capítulo específico sobre o Sistema Nacional de Educação e também de dispositivos que se caracterizem como referenciais nacionais de qualidade para: (a) uma base nacional comum que oriente a formação docente e os processos de avaliação da aprendizagem; (b) a estrutura e o funcionamento de estabelecimentos escolares; (c) a valorização profissional e a avaliação institucional; e (d) a gestão democrática, no seu sentido amplo, incluindo 
o funcionamento de conselhos, fóruns, instancias de negociação e as conferências de educação.

(II) Regulamentação do artigo 23 da Constituição Federal, ou uma Lei de Responsabilidade Educacional, para que os referenciais de qualidade definidos na LDB sejam garantidos e a a organização da educação nacional se dê em Regime de Colaboração.

(III) Adequação das regras de financiamento, para um novo FUNDEB, com mais equidade e efetividade do Piso Salarial Profissional Nacional da Educação Básica, contando com a ampliação do aporte de recursos da União.

(IV) Adequação dos sistemas de ensino às novas regras nacionais, para alcançar a descentralização qualificada no Sistema Nacional de Educação, ação distributiva e supletiva sustentada no princípio da cooperação federativa, que equilibre qualidade com equidade e identidade nacional com identidade local na educação básica.

No horizonte da agenda institutinte, desenhada neste documento, está a possibilidade de que "em junho de 2016 ainda não tenhamos todas as quatro dimensões de trabalho finalizadas, especialmente a adequação dos sistemas subnacionais", porém há expectativa de que seja viável alcançar as demais, com proposições concertadas entre os entes federativos, os educadores e a sociedade, que possam se apresentar legítimas e, por conseguinte, encontrar eco no Congresso Nacional.

Esta é a proposta inicial de concepção do Sistema Nacional de Educação, derivada da agenda do Plano Nacional de Educação 2014-2024, fruto de dedicado trabalho da SASE/MEC, em diálogo com as entidades representativas de todo o País. O texto autoral dos dirigentes da SASE/MEC teve a colaboração de Carlos Augusto Abicalil, Carlos Roberto Jamil Cury, Luiz Fernandes Dourado e Romualdo Luiz Portela de Oliveira, sendo concluído em junho de 2015 e tornado público em http://pne.mec.gov.br/images/pdf/SNE_junho_2015.pdf desde 17/06/2015, no portal eletrônico "Planejando a Próxima Década - construindo os planos de educação".

\section{DO LEGADO NORMATIVO}

É oportuno, a par do conteúdo de ambos os documentos, recuperarmos linhas gerais de configurações político-administrativas anteriores, plasmadas na legislação, pois o legado de estruturas e políticas prévias guarda, em geral, a possibilidade de contribuir para pensar os desafios daquilo que se coloca como instituinte ou a instituir em dado momento histórico.

Resenhamos, pois, neste item legislação de âmbito nacional, de um período historicamente recente, relacionada à organização da educação brasileira em sistemas de ensino, com referências, igualmente, a responsabilidades educacionais dos níveis de governo da federação que guardem estreita relação 
com essa organização. Iniciaremos com a Lei de Diretrizes e Bases da Educação Nacional (LDB) de 1961, por ser o primeiro documento legal a reunir todos os níveis da educação e a detalhar mais amplamente a administração e os sistemas de ensino.

A Lei n. ${ }^{\circ}$ 4.024/61 preceituou a organização de sistemas de ensino pela União e pelos estados, assim como a ação federal supletiva, versando, mais longamente, sobre condições e responsabilidades para o reconhecimento e inspeção dos estabelecimentos de ensino pelos estados e pela União. Essa Lei também afirmou que as atribuições do poder público federal em matéria de educação seriam exercidas pelo Ministério da Educação e da Cultura, ao qual caberia “... velar pela observância das leis do ensino e pelo cumprimento das decisões do Conselho Federal de Educação [CFE]"(art. 7º); ao CFE foram conferidas competências que abrangiam definições curriculares, supervisão das instituições de ensino, estudos e medidas para expansão do ensino ou melhoria de sua qualidade, bem como a elaboração de planos de educação para aplicação dos recursos dos fundos federais da educação.

Na sequência, a Emenda Constitucional n. ${ }^{\circ}$ 01/69 reiterou a organização dos sistemas de ensino pelos estados e pela União; incumbiu à União prestar assistência técnica e financeira para o desenvolvimento dos sistemas estaduais; o sistema federal de ensino deveria ter caráter supletivo, com a conotação de atuação da União na educação escolar "nos estritos limites das deficiências locais" (art. 177).

A Lei n. $.^{\circ} 5.692 / 71$, de diretrizes e bases do ensino de $1^{\circ}$ e $2^{\circ}$ graus, embora não tenha contemplado segmento específico sobre a organização político-administrativa dos sistemas de ensino, tratou de aspectos organizacionais das relações intergovernamentais na educação escolar. Com efeito, essa Lei elegeu o planejamento como instrumento central para as ações no setor educacional. Determinou a elaboração de planos nacionais setoriais, em consonância com os planos gerais de governo, para nortear os programas federais e a assistência aos estados, assim como a decorrente formulação de planos de educação estaduais e municipais, estes como condição para concessão de auxílios federais aos sistemas estaduais ou aos programas de educação dos municípios. Essa lei fixou, inclusive, o seguinte objetivo para o apoio financeiro federal aos sistemas estaduais:

[...] corrigir as diferenças regionais de desenvolvimento socioeconômico, tendo em vista a renda per-capita e a população a ser escolarizada, o respectivo estatuto do magistério, bem como a remuneração condigna e pontual dos professores e o progresso quantitativo e qualitativo dos serviços de ensino verificado no biênio anterior (art. 54, parágrafo $1^{\circ}$ ). 
No texto constitucional promulgado em 1988, ficou definido que as esferas de governo devem organizar seus sistemas de ensino em regime de colaboração. Nesta formulação foi reconhecida a possibilidade de constituição de sistemas municipais de ensino, coerente com a nova posição dos municípios como entes da federação. No âmbito do planejamento, foi preceituada a elaboração, em lei, de planos nacionais de educação.

As emendas constitucionais n..$^{\circ}$ 14/96, 53/06 e 59/09 alteraram o texto de $1988 \mathrm{em}$ aspectos diretamente relacionados às (co)responsabilidades das esferas de governo na educação. Ficaram então (re)definidos: as prioridades de atuação de cada esfera de governo; papel, objetivos e instrumentos do apoio da União aos estados e municípios na educação; o comprometimento da União e dos estados, por meio de assistência técnica e financeira, com a manutenção de programas municipais de educação infantil e de ensino fundamental; a necessidade de instituição de formas de colaboração para a universalização do ensino obrigatório; fundos de redistribuição de recursos para financiamento do ensino fundamental (emenda 14/96) e da educação básica (emenda 53/06); a possibilidade de edição de lei complementar que regulamente a cooperação federativa na educação; a articulação do sistema nacional de educação em regime de colaboração como objetivo central dos planos nacionais de educação, a realizar-se por meio de ações integradas das diferentes esferas de governo. A instituição do Sistema Nacional de Educação, previsto na Constituição Federal a partir da emenda n ${ }^{\circ}$ 59/09, demanda detalhamento do traçado institucional estabelecido na atual LDB, hoje denominado organização da educação nacional.

A Lei n ${ }^{\circ}$ 9.394/96 (LDB) delineia uma organização da educação nacional com a previsão de existência dos sistemas federal, estaduais e municipais de ensino, os quais têm responsabilidades próprias ou compartilhadas, devendo organizarse em regime de colaboração. São três níveis que, pelas determinações desta lei, articulam-se - nos campos da provisão de serviços (oferta), do planejamento, do financiamento, da normatização e da avaliação - por competências coordenadas pela União. Esta articulação foi prevista sem que, no entanto, fossem explicitados suficientes meios institucionais articuladores para a colaboração/cooperação entre os governos e os sistemas de ensino.

Cabe um parênteses para lembrar algumas modificações operadas no texto da LDB ao longo de seus oito anos de tramitação no Congresso Nacional. Substitutivos em pauta até 1993 continham uma concepção de organização da educação nacional na qual a diretriz democrática de constituição de um sistema nacional era desdobrada em instrumentos concretos e permanentes para que a formulação e o acompanhamento da política educacional fossem tarefas a congregar governos e sociedade civil. 
A composição e atribuições do Conselho Nacional de Educação e do Fórum Nacional de Educação, previstos no projeto de LDB aprovado na Câmara de Deputados em 1993, eram elemento central para a constituição democrática de um sistema nacional de educação. Contudo, o texto finalmente aprovado previu apenas a organização da educação nacional sob forma sistêmica, compreendendo os sistemas da União, dos estados e dos municípios. A organização sistêmica expressa-se pela observância de princípios comuns aos diferentes sistemas e pela definição de instâncias com competências articuladoras, coordenadoras ou consultivas.

No que concerne ao planejamento, a Lei no 10.172/2001, que aprovou o Plano Nacional de Educação 2001-2011, fixou objetivos e metas que requeriam ações articuladas de todos os níveis de governo, indicando explicitamente aqueles que exigiam iniciativa ou colaboração da União; pode-se depreender que os demais seriam atingidos por meio de ações dos governos subnacionais. Não houve menção a Sistema Nacional de Educação, mas foi um passo importante na especificação de (co)responsabilidades das esferas governamentais na educação, alargando-se o campo de possibilidades dos objetos e instrumentos de cooperação e colaboração entre governos e entre sistemas de ensino.

O Plano Nacional de Educação do decênio 2014-2024 - Lei no 13.005/2014 -, em observância à Constituição Federal, como ora atualizada, estabelece uma série de diretrizes e instrumentos que remetem à construção do Sistema Nacional de Educação, o que envolve tanto atribuições e relações mais institucionalizadas de/entre níveis de governo e poderes do Estado quanto entre instâncias governamentais e sociedade civil. Preceitua a elaboração de lei específica para a instituição do Sistema Nacional de Educação, mas demanda também a costura dessa lei com outros instrumentos normativos, o que, no seu conjunto, poderá ensejar o novo, que seria uma perspectiva mais complexa e orgânica sistema nacional - do que a justaposição de sistemas de ensino.

\section{DA ARENA INSTITUINTE}

Essa remissão ao normativo evidencia o instituído mas não podemos deixar de perceber e valorizar o processo político pelo qual nos foi legado. As arenas do debate foram muitas e complexas, nossa capacidade de conhecê-las e de nelas atuar tem crescido, mas há muito mais a nos desafiar. Por isso, cabe indagar: que tipo de arena(s) politica(s) é possível visualizar, pelo menos de modo preliminar, nas deliberações acerca do Sistema Nacional de Educação?

Uma das tipologias na análise de políticas públicas é a de Theodore Lowi (1992), a qual, dentro da concepção de arena (policy arena), distingue quatro 
áreas de política, de acordo com o potencial de geração de conflito, de apoio ou de rejeição, dado pela incidência mais direta ou indireta no comportamento dos afetados ou no entorno. As arenas agrupam políticas de acordo com sua característica mais acentuada: distributiva, redistributiva, regulamentadora ou constitutiva. Potencialmente, cada tipo seria processado de modo diverso dentro do sistema político, conformando arenas mais ou menos conflitivas. Ou seja, a ideia é que o caráter ou natureza da política influencia o jogo político, quer dizer, o tipo de arena em que vão ser processadas decisões e ações, o que acrescenta um novo elemento às concepções de maior influência das instituições ou da política (politics) nas políticas públicas ${ }^{4}$.

Embora seja uma tipologia de difícil aplicação aos casos concretos, e tendo em conta a interveniência de contextos específicos, podemos aventar a possibilidade de que as normas de um Sistema Nacional de Educação e das responsabilidades e cooperação federativas na educação configurem uma política constitutiva, pois se trata de definir regras de distribuição de competências entre esferas de governo, de relações intergovernamentais e de participação social em decisões/ações públicas.

A tendência, segundo Frey (2000), é que este tipo de política provoque um impacto moderado na esfera pública, pois, muitas vezes, os debates e embates ficam mais restritos ao próprio sistema político-administrativo, ou seja, não envolvem segmentos mais amplos da sociedade. Parece plausível essa hipótese, é difícil vislumbrar uma grande mobilização nacional em torno do assunto, mas cabe que lancemos um olhar, então, sobre atores do sistema político-administrativo e da sociedade civil supostamente mais interessados na problemática.

Atores dos poderes executivos de todas as esferas de governo, sem dúvida têm envolvimento significativo, pois as regras do Sistema Nacional de Educação e das responsabilidades federativas na educação, ao obrigarem a isto ou aquilo, afetam diretamente os executivos; por certo dirigentes do setor educacional de todos os níveis de governo são protagonistas, mas não somente, pois é de prever intensa ação dos gabinetes da Presidência da República, de governadores e de prefeitos, bem como dos setores governamentais, de todas as latitudes, responsáveis por decisões de finanças públicas.

No legislativo federal, os presságios não parecem favoráveis. $\mathrm{Na}$ atual legislatura, além de uma composição partidário-ideológica mais à direita e ao centro do continum esquerda-direita, as agendas decisórias tem sido marcadas por duros embates e barganhas com o Executivo. Neste quadro, são bastante incertas as possibilidades de instauração de um processo qualificado de exame da 
matéria, o que provavelmente exigirá muito empenho dos setores educacionais que propõem e demandam avanços na democratização da educação do país pela via do Sistema Nacional de Educação e da cooperação federativa.

Um terceiro bloco a mencionar reúne entidades da sociedade civil e intelectuais que, de modo mais particular, dialogam com essas ou com setores governamentais, na qualidade de especialistas. São atores de diferentes matizes ideológicos, numa gradação que, grosso modo, vai de concepções (neo) conservadoras e/ou (neo)liberais a ideários do bem-estar social e do socialismo. $\mathrm{O}$ assunto em pauta pode mobilizar esses setores de distintos modos, como têm ocorrido nos últimos anos em diversas arenas de deliberação normativa das políticas educacionais, como por ocasião da apreciação do financiamento da educação básica e da educação superior como do próprio Plano Nacional de Educação. Almejamos que os setores mais à esquerda tenham aglutinação e força suficiente na permeabilidade do Executivo e do Congresso Nacional para sustentar as propostas mais favoráveis a avanços na garantia de mais igualdade e mais responsabilidade pública na educação.

\section{UM TEMPO DE AFLUÊNCIAS}

As relações federativas e as configurações institucionalizadas dos sistemas de ensino e as autonomias das escolas e universidades requerem contínuo estudo no reconhecimento dos seus atores mais valentes e na produção das estratégias pelas quais se poderá conquistar a sua participação no movimento instituinte do Sistema Nacional de Educação, no sentido em que aqui está sendo postulado.

Cremos que se trata de uma mudança paradigmática no mandato político da educação - escola com padrão de qualidade para todos. As conquistas no acesso à escola têm sido muitas mas muitos também os tropeços e as derrotas de muitos; sabemos, assim, que a luta por maior intensidade democrática na e pela educação é processo em que, por meio de debates e embates, nos fazemos seus sujeitos porque nela implicados.

O desafio está posto! Honrar o instituído, alçando-o a um patamar de maior densidade conceitual e democrática, fazendo valer o princípio da cooperação federativa com unidade e diversidade nos meios e formas organizacionais que melhor garantam o direito de todos à educação em condições de equidade.

\section{REFERÊNCIAS}

BRASIL. Constituição. Constituição da República Federativa do Brasil., de 05 de outubro de 1988 (preceitos sobre a educação, na redação original e com a 
atualização dada pelas Emendas Constitucionais 14/96, 53/06, 59/09).

Constituição da República Federativa do Brasil, de 17 de outubro de 1969.

Lei $\mathrm{n}^{\circ}$ 13.005, de 13 de junho de 2014. Aprova o Plano Nacional de Educação.

Lei N. ${ }^{\circ} \mathbf{1 0 . 1 7 2}$, de 09 de janeiro de 2001. Aprova o Plano Nacional de Educação e dá outras providências.

Lei N. ${ }^{\circ}$ 9.394, de 20 de dezembro de 1996. Estabelece as diretrizes e bases da educação nacional.

Lei N. ${ }^{\circ}$ 5.692, de 11 de agosto de 1971. Fixa as diretrizes e bases para o ensino de $1^{\circ}$ e $2^{\circ}$ graus e dá outras providências.

Lei N. ${ }^{\circ}$ 4.024, de 20 de dezembro de 1961. Fixa as diretrizes e bases da educação nacional.

CÂMARA DOS DEPUTADOS. Comissão de Educação, Cultura e Desporto. Lei de Diretrizes e Bases da Educação Nacional - Redação final do Projeto de Lei 1.258-C/88, que fixa diretrizes e bases da educação nacional. Brasilia, Centro de Documentação e Informação, Coordenação de Publicações, 1993.

FARENZENA, Nalú. A política de financiamento da educação básica: rumos da legislação brasileira. Porto Alegre: Editora da UFRGS, 2006.

FREY, Klaus. Políticas públicas: um debate conceitual e reflexões referentes à prática da análise de políticas públicas no Brasil. Planejamento e Políticas Públicas. Brasília, IPEA, n. 21, p. 211-259, jun. 2000.

MEC/SASE. Ministério da Educação. Secretaria de Articulação com os Sistemas de Ensino. Instituir um Sistema Nacional de Educação: agenda obrigatória para o país. Brasília, junho de 2015. Disponível em:

http://pne.mec.gov.br/images/pdf/sase_mec.pdf.

MEC/SASE. Ministério da Educação. Secretaria de Articulação com os Sistemas de Ensino. O Sistema Nacional de Educação. Brasília, julho de 2014. 
Disponível em: http://pne.mec.gov.br/images/pdf/SNE_junho_2015.pdf

MEDEIROS, Isabel L.P.; LUCE, Maria Beatriz. Gestão democrática na e da educação: concepções e vivências. In: LUCE, Maria Beatriz; MEDEIROS, Isabel L.P. Gestão escolar democrática: concepções e vivências. Porto Alegre: Editora da UFRGS, 2006, p. 16-25.

MULLER, Pierre, SUREL, Ives. Análise das políticas públicas. Pelotas : EDUCAT, 2002.

SANTOS, Boaventura de Sousa. A crítica da razão indolente: contra o desperdício da experiência. São Paulo: Cortez, 2000.

MARIA BEATRIZ LUCE é doutora (PhD) em Educação pela Michigan State University e professora titular de Política e Administração da Educação na Universidade Federal do Rio Grande do Sul. E-mail: lucemb@ufrgs.br

NALÚ FARENZENA é doutora em Educação pela Universidade Federal do Rio Grande do Sul e professora associada de Política e Administração da Educação na mesma instituição. E-mail: nalu.farenzena@ufrgs.br

Recebido em outubro de 2015 Aprovado em dezembro de 2015 